\title{
ICD-O Tumor Topography Code
}

National Cancer Institute

\section{Source}

National Cancer Institute. ICD-O Tumor Topography Code. NCI Thesaurus. Code

C160903.

A code for the primary site of a tumor being reported using either ICD-O-2 or ICD-O-3. 